\author{
Charles L. Sprung
}

\title{
Randomized controlled trials and practice guidelines: the good, the bad, and the ugly
}

Received: 16 September 2012

Accepted: 16 September 2012

Published online: 12 October 2012

C) Springer-Verlag Berlin Heidelberg and ESICM 2012

This editorial refers to the article available at: doi:10.1007/s00134-012-2720-z.

\section{L. Sprung $(\bowtie)$}

General Intensive Care Unit, Department of Anesthesiology and Critical Care Medicine, Hadassah Hebrew University Medical Center, P.O. Box 12000, 91120 Jerusalem, Israel

e-mail: charless@ekmd.huji.ac.il
Mortality from septic shock remains high, between 24 and $53 \%$ [1-3]. From 2002, the Surviving Sepsis Campaign (SSC) has attempted to decrease sepsis mortality by increasing awareness and issuing management guidelines that promote prompt identification and early, evidencebased treatment [4-7]. The SSC claims success with a decrease in hospital mortality over 2 years from 37 to $31 \%$ through increased compliance with their guideline bundles [8]. Questions, however, arose as to whether this outcome benefit was specifically related to the intervention as bundles included treatments subsequently found not to be beneficial (low-dose steroids [3], tight glucose control [9], and drotrecogin alfa (activated) [1]), overall compliance remained low, there was no control group, and sepsis outcomes were improving without the SSC owing to advances in critical care management [10].

In this issue of Intensive Care Medicine, Casserly et al. [11] report the effect of the SSC's corticosteroid guidelines on clinical practice and patient outcomes. From 2005 to 2010 , of 17,847 septic patients given vasopressor therapy despite fluid resuscitation, low-dose steroids were commonly administered (50\%); however, their use decreased after publication of Corticus [3] and the 2008 recommendations [6]. Of note, steroids were associated with a greater adjusted hospital mortality. Limitations of the study include the lack of severity scoring for each patient, the possibility that steroid-treated patients may have been more severely ill, missing data for potential confounders, and no control group. The authors correctly note that although an observational study cannot refute the results of randomized controlled trials, the findings do provide valuable information regarding treatment effectiveness.

When should corticosteroids be given in septic shock? Two large prospective studies of low-dose steroids have influenced recommendations. Annane et al. [12] demonstrated improved 28-day survival in more severely ill patients who remained with systolic blood pressures (SBP) below $90 \mathrm{mmHg}$ for longer than $1 \mathrm{~h}$ despite therapy. Corticus [3] showed no 28-day mortality difference albeit in patients with a broader range of shock severity and in whom a longer time window was allowed for steroid commencement. Both studies noted faster shock reversal for patients receiving steroids, notwithstanding the outcome differences [3, 12]. Recent meta-analyses confirmed no difference in mortalities but improved shock reversal [13, 14]. The 2004 SSC recommendations suggested corticosteroids for all septic shock patients requiring vasopressor therapy to maintain an adequate blood pressure despite adequate fluid replacement [5]. By 2008 this was modified to use only in patients whose blood pressure is poorly responsive to fluid and vasopressor therapy [6]. The 2012 guidelines recommend that steroids not be used if adequate fluid and vasopressor therapy restore hemodynamic stability but suggest hydrocortisone if hemodynamic stability is not achievable [7]. In our unit, low-dose steroids are used only for septic shock patients whose SBP remains below $90 \mathrm{mmHg}$ for longer than $1 \mathrm{~h}$ which were the entry criteria into the Annane [12] study which showed a benefit. 
It is accepted that corticosteroids should generally not be used to treat sepsis in the absence of shock [5-7]. Some physicians still use steroids to reverse shock but one wonders if this strategy is worthwhile if it does not increase survival and may lead to superinfections and new sepsis episodes.

How should restoration of hemodynamic stability or responsiveness to therapy be determined? Should it be based on vasopressor dose, requirement for multiple agents, or the trend in vasopressor requirements? Perhaps more clinically pertinent factors should be used such as evidence of adequate perfusion (e.g., urine output). Unfortunately, the SSC only provides general recommendations that are open to different interpretations depending on the clinician's preference or dislike of steroids.

Practice guidelines are likely to be beneficial as they improve quality of care and outcomes, promote interventions of proven benefit, discourage ineffective, outdated treatments, advance consistent care, enhance decisionmaking with explicit recommendations, provide the latest literature, and highlight further research requirements [15]. Guidelines such as the SSC use an evidence-based approach assessing the quality of evidence to determine the strength of recommendations. The randomized controlled trial provides the greatest quality of evidence to determine proven benefit. The outcome effect, however, applies to the overall study population. An individual patient may respond in the opposite direction while those falling outside the often strict trial inclusion criteria may also respond differently. Recommendations are influenced by the opinions, experience, and composition of the group producing the guidelines [15] so that recommendations developed by consensus may not always be best. Some committees may be self-serving and biased. Limitations to guidelines thus include the inability to individualize patient therapy, recommendations serving societal and not patient needs, protecting special interest groups, and lagging behind medical progress [15]. The Institute of Medicine recently issued standards for developing clinical practice guidelines incorporating conflicts of interest, appraisals of evidence, and the rigor of the evaluations [16].

Evaluations of practice guidelines have not stressed several issues. First is the generalizability of recommendations to larger populations than originally studied. The original studies of corticosteroids, tight glucose control, and early goal-directed therapy were not performed in the patients for whom the SSC recommendations were made [5]. The second is the impact of guidelines on recruiting patients into subsequent trials. The 2004 SSC steroid recommendations were based on grade $\mathrm{C}$ evidence yet many doctors blindly accepted this recommendation and treated all septic shock patients with steroids, thus affecting enrollment in the Corticus trial.

What can improve the situation? When developing guidelines care should be taken to not over-extrapolate from the patient populations used in the considered studies, especially those from single centers. Organizations developing guidelines should advocate enrollment of patients into clinical trials rather than following guidelines with lower grades of evidence or weak recommendations. As the definitive study of corticosteroids in septic shock has yet to be performed and the current 2012 SSC guidelines for steroids are graded $2 \mathrm{C}$, all eligible septic shock patients should be enrolled into The ADjunctive coRticosteroid trEatment iN criticAlly ilL patients with septic shock (ADRENAL, NCT01448109) trial. We should learn from history, not repeat it. Hopefully, then a high grade guideline for steroid use in septic shock with consensus rather than controversy will be obtained.

Conflicts of interest Charles L. Sprung was the coordinator of the Corticus study and was a member of the SSC Steering Committee (2002-2005) and a member of the SSC Guidelines Committees of 2004, 2008, and 2012.

\section{References}

1. Ranieri VM, Thompson BT, Barie PS, Dhainaut JF, Douglas IS, Finfer S, Gårdlund $\mathrm{B}$, Marshall $\mathrm{JC}$, Rhodes $\mathrm{A}$, Artigas A, Payen D, Tenhunen J, AlKhalidi HR, Thompson V, Janes J, Macias WL, Vangerow B, Williams MD, PROWESS-SHOCK Study Group (2012) Drotrecogin alfa (activated) in adults with septic shock. N Engl J Med 366:2055-2064

2. De Backer D, Biston P, Devriendt J, Madl C, Chochrad D, Aldecoa C, Brasseur A, Defrance P, Gottignies P, Vincent JL, SOAPII Investigators (2010) Comparison of dopamine and norepinephrine in the treatment of shock. N Engl J Med 362:779-789
3. Sprung CL, Annane D, Keh D, Moreno R, Singer M, Freivogel K, Weiss YG, Benbenishty J, Kalenka A, Forst H, Laterre PF, Reinhart K, Cuthbertson $\mathrm{BH}$, Payen D, Briegel J, CORTICUS Study Group (2008) Hydrocortisone therapy for patients with septic shock. N Engl J Med 358:111-124

4. Slade E, Tamber PS, Vincent JL (2003) The Surviving Sepsis Campaign: raising awareness to reduce mortality. Crit Care $7: 1-2$
5. Dellinger RP, Carlet JM, Masur H, Gerlach H, Calandra T, Cohen J, GeaBanacloche J, Keh D, Marshall JC, Parker MM, Ramsay G, Zimmerman JL, Vincent JL, Levy MM (2004) Surviving Sepsis Campaign guidelines for management of severe sepsis and septic shock. Intensive Care Med 30:536-555 
6. Dellinger RP, Levy MM, Carlet JM, Bion J, Parker MM, Jaeschke R, Reinhart K, Angus DC, Brun-Buisson C, Beale R, Calandra T, Dhainaut JF, Gerlach H, Harvey M, Marini JJ, Marshall J, Ranieri M, Ramsay G, Sevransky J, Thompson BT, Townsend S, Vender JS, Zimmerman JL, Vincent JL (2008) Surviving Sepsis Campaign: international guidelines for management of severe sepsis and septic shock. Intensive Care Med 34:17-60

7. Dellinger RP, Levy MM, Rhodes A, Annane D, Carcillo JA, Gerlach H, Opal S, Sevransky J, Sprung CL, Douglas IS, Jaeschke R, Osborn TM, Nunnally M, Townsend SR, Reinhart K, Kleinpell RM, Angus DC, Deutschman CS, Machado FR, Rubenfeld G, Webb S, Beale RJ, Vincent JL, Moreno R, the Surviving Sepsis Campaign Committee (2012) Surviving Sepsis Campaign: international guidelines for management of severe sepsis and septic shock. Intensive Care Med 39 (in press)
8. Levy MM, Dellinger RP, Townsend SR, Linde-Zwirble WT, Marshall JC, Bion J, Schorr C, Artigas A, Ramsay G, Beale R, Parker MM, Gerlach H, Reinhart K, Silva E, Harvey M, Regan S, Angus DC (2010) The Surviving Sepsis Campaign: results of an international guideline-based performance improvement program targeting severe sepsis. Intensive Care Med 36:222-231

9. The NICE-SUGAR Study Investigators (2009) Intensive versus conventional glucose control in critically ill patients N Engl J Med 360:1283-1297

10. Finfer S (2010) The Surviving Sepsis Campaign: robust evaluation and highquality primary research is still needed. Intensive Care Med 36:187-189

11. Casserly B, Gerlach H, Phillips GS, Lemeshow S, Marshall JC, Osborn TM, Levy MM (2012) Low-dose steroids in adult septic shock: results of the Surviving Sepsis Campaign. Intensive Care Med. doi: $10.1007 / \mathrm{s} 00134-012-2720-\mathrm{z}$
12. Annane D, Sébille V, Charpentier C, Bollaert PE, François B, Korach JM, Capellier G, Cohen Y, Azoulay E, Troché G, Chaumet-Riffaud P, Bellissant E (2002) Effect of treatment with low doses of hydrocortisone and fludrocortisone on mortality in patients with septic shock. JAMA 288:862-871

13. Sligl WI, Milner DA Jr, Sundar S, Mphatswe W, Majumdar SR (2009) Safety and efficacy of corticosteroids for the treatment of septic shock: a systematic review and meta-analysis. Clin Infect Dis 49:93-101

14. Patel GP, Balk RA (2012) Systemic steroids in severe sepsis and septic shock. Am J Respir Crit Care Med 185:133-139

15. Woolf SH, Grol R, Hutchinson A, Eccles M, Grimshaw J (1999) Potential benefits, limitations and harms of clinical guidelines. BMJ 318:527-530

16. Institute of Medicine standards (2011) Clinical practice guidelines we can trust. The National Academies Press, Washington, DC 